Niladri Basu ORCID iD: 0000-0002-2695-1037

\title{
TITLE
}

\section{Factors affecting the perception of New Approach Methodologies (NAMs) in the ecotoxicology community}

\author{
Authors \\ Matthieu Mondou, Gordon M. Hickey, H.M. Tuihedur Rahman, Steve Maguire, \\ Guillaume Pain, Doug Crump, Markus Hecker, Niladri Basu
}

\section{ACKNOWLEDGEMENTS}

We thank the financial sponsors of this research project: Genome Canada, Génome Québec, Genome Prairie, the Government of Canada (Environment and Climate Change Canada), le ministère de l'Économie et de l'Innovation du Québec, the University of Saskatchewan, McGill University and the Social Sciences and Humanities Research Council of Canada (SSHRC). We would also like to acknowledge valuable comments from Heike Laue, Erick Lachapelle, and Vincent Arel-Bundock.

\section{DATA ACCESSIBILITY STATEMENT}

The data is not publicly available. We collected our own survey data and it is subject to a procedure that has been approved by the McGill University Ethics Board to safeguard the privacy of the participants.

We can provide more details on the data, if requested by reviewers or editors, as appropriate per the McGill Ethics Board approval.

Please contact the primary author for inquiries.

\section{INTRODUCTION}

Over the last four decades, environmental toxicity testing in support of regulatory decision-making has crystalized into a set of highly codified practices and standardized protocols. While conventional risk assessment methods (relying primarily on whole

This is the author manuscript accepted for publication and undergone full peer review but has not been through the copyediting, typesetting, pagination and proofreading process, which may lead to differences between this version and the Version of Record. Please cite this article as doi: 10.1002/ieam.4244.

This article is protected by copyright. All rights reserved. 
animal in vivo assays) are useful for determining acceptable thresholds for chemicals, they have notable drawbacks, including being very expensive, time-consuming and requiring the use of large numbers of live animals (Basu et al. 2019). These limitations have created a situation where most synthetic chemicals entering the environment are considered “data poor” (Hartung 2011). The need for faster, less expensive and more ethical risk assessment approaches has been formally recognized (National Research Council 2007), with alternative options - commonly referred to as 'New Approach Methodologies (NAMs)' - becoming increasingly available. Following the outcome of an ECHA international scientific workshop, New Approach Methodologies (NAMs) are defined broadly as "in silico approaches, in chemico and in vitro assays including highthroughput and high-content techniques, omics with a focus on metabolomics" (ECHA 2016a: 47). While international initiatives to 'modernize' toxicity testing are multiplying and gathering momentum (Arnold 2015; ECHA 2016a; ICCVAM 2018; Kavlock et al. 2018), the formal adoption and deployment of NAMs in chemical risk assessment generally remains limited. This situation represents an increasing source of frustration and topic of debate among different actors within the community of practice engaged in chemical risk assessment (Vachon et al. 2017; Zaunbrecher et al. 2017).

The Society of Environmental Toxicology and Chemistry (SETAC) is a global organization bringing together approximately 5,200 members from academia, government, industry and NGOs in 80 countries. For scientists and professionals working in the fields of environmental toxicology, SETAC is a key forum for exchange, where advances in toxicity testing and risk assessment practices are demonstrated, discussed and - potentially - diffused. There has, however, been limited empirical research on the contemporary viewpoints and perspectives of SETAC members regarding NAMs and their potential role in enhancing regulatory environmental toxicology.

In this article we draw on original data to explore the experiences and perspectives of participants at SETAC-organized events in order to assess: 1) how NAMs are discussed in comparison to conventional testing methods; and 2) how participants at SETAC-organized events view the viability of NAMs. The aim of our study was to assess the perspectives of a broad cross section of the environmental toxicology community concerning the viability of various NAMs for regulatory use and decision-making. Our analysis also explores some of the sociological factors that may help explain why certain approaches are deemed more or less viable by different actors. We then discuss the implications of our findings for the environmental toxicology community more broadly. Throughout the article, we use the term 'toxicology' to denote "the study of the adverse effects of chemical, physical, or biological agents on living organisms and the ecosystem” (Woolley and Woolley 2017: 9).

\section{The need for New Approach Methodologies (NAMs)}

Given current legislative mandates in North America (Chemicals Management Plan in Canada, and Toxic Substances Control Act in the US) and Europe (Registration, Evaluation, Authorisation and Restriction of Chemicals) and the slow pace at which conventional testing proceeds, there is a need to accelerate the pace of chemical risk assessment (Kavlock et al. 2018). The gap between these legislative mandates and the

This article is protected by copyright. All rights reserved. 
number of chemical substances in need of toxicity data is large and widening (Basu et al. 2019). The United States EPA estimated that using whole animal testing for a single chemical can take four years and cost between \$1 and \$20M USD (Martin et al. 2012). Such resource demands are a major obstacle to reaching current legislative mandates to manage chemicals. Therefore, governments and businesses are increasingly interested in NAMs that promise to reduce animal use, costs and delays in chemical testing (Bradbury et al. 2004; Krewski et al. 2010). NAMs that are currently being considered, or experimented with, by regulatory agencies include In silico approaches (e.g. (Q)SARs, physiological toxicokinetic modeling), In vitro testing (e.g. cell-based, cell-free or biochemical assays), In vivo early life stage (ELS) testing (e.g. whole animal exposures prior to independent feeding); 'Omics approaches (e.g. genomics, transcriptomics, metabolomics, proteomics) and high throughput screening.

The use, acceptance and validation of NAMs have been discussed in the toxicology community for at least 20 years (Zeiger 1999; Freeman 2004; Waters and Fostel 2004; Ankley et al. 2006; Council of Canadian Academies 2012; ECHA 2016a; Whelan and Eskes 2016; Sauer et al. 2017 Sep). Regulatory acceptance is generally considered more likely if the NAM has 'relevance', which means that it can be clearly linked to the regulator's operationalized protection goal, and 'reliability', which can be enhanced by ensuring technical guidance documents are available to regulators. But the adoption of a NAM does not depend solely on its attributes, as features of the adopting system, including organizational and institutional factors, also need to be addressed in order to realize a shift towards greater use of NAMs in chemical risk assessment (National Toxicology Program 2004; Environment and Climate Change Canada 2016; Busquet and Hartung 2017; ICCVAM 2018; Standing Committee on Emerging Science for Environmental Health Decisions et al. 2018; Tickner et al. 2018). Furthermore, previous surveys concerning the perceptions of NAMs within the toxicology community have provided a portrait of perceived drivers and obstacles, and demographics tied to the use and level of knowledge about NAMs (Vachon et al. 2017; Zaunbrecher et al. 2017). Vachon et al.'s (2017) survey of Canadian human health risk assessors $(n=29)$ revealed that familiarity with, and use of, toxicogenomics was very low. The authors suggested that a lack of guidelines regarding data interpretation and a lack of organizational leadership to promote the use of toxicogenomics might be causes of this limited uptake. Zaunbrecher et al.'s (2017) survey of toxicology professionals $(n=1,381 ; 75 \%$ of which were from North America) reported that between 26\% and 86\% (depending on the method and application) of respondents used alternative testing strategies or believed that different alternative testing strategies were viable. Regulatory acceptance and difficulties interpreting data were the main barriers to adoption identified by respondents. A significant driver for adoption was educational cohort, where more recent university graduates tended to view alternatives as being more viable. These contributions offer useful insights to the factors tied to the adoption of NAMs, however, as noted by Zaunbrecher et al. (2017), "further inquiry will be necessary to dissect the root of the differences in perception". Our study builds on this observation, aiming to further understand some of the social dynamics affecting the uptake of novel scientific methods in regulatory risk assessment.

This article is protected by copyright. All rights reserved. 
REVISED - December 2019

\section{The need for research on the social acceptance of NAMs}

To identify the root of different perceptions concerning the viability of NAMs in the environmental toxicology community, we sought to investigate the social factors that could influence the perception of NAMs. To do this, we operationalized five factors leveraged from previous studies on the interface between science and public policy and from science and technology studies (STS): 1) professional profile of user; 2) internal science communication within professional forums; 3) concern for 'error cost' in regulatory decision-making; 4) collaboration across stakeholders, and 5) fundamental/paradigmatic beliefs regarding toxicology. We further explain each of these factors below.

Professional profile in the environmental toxicology community (educational cohort, type of employer) is the first and most well-studied potential factor influencing community perceptions of NAMs. Vachon et al. (2017) reported that most of their Canadian risk assessor respondents did not have any training in toxicogenomics. Zaunbrecher et al. (2017) reported a positive correlation between perceived viability of alternatives and degree year demonstrating that as new individuals enter the community, the overall skills and education background of professionals change. Given that NAMs are relatively recent additions to the curriculum in environmental toxicology-related university programs, professionals having graduated with older cohorts may not have the same level of familiarity and knowledge regarding NAMs than more recent graduates, potentially influencing perceptions of viability. The type of employer may also influence perceptions of NAM viability through a number of mechanisms, including prevailing levels of familiarity among workplace colleagues with the new tools, professional norms, and organizational practices. From a regulatory point of view, environmental toxicology is a professional field that operates within clear policy and legal frameworks designed to guide decision-making in national contexts, with the acceptable/ preferred methods of risk assessment subject to broader democratic processes that may or may not reflect international scientific perspectives. We could therefore expect perceptions of viability to vary between actors who are more subjected to these processes (e.g., government and industry risk assessors) and those that have more freedom to operate beyond the existing regulatory frameworks (e.g., academics and students).

Internal science communication within professional fora of prestige is potentially important to the acceptance of new regulatory test methods because such fora serve as arenas for continuing education and provide opportunities for young and well-established professionals alike to become more familiar with new test methods (Fischer and Leifeld 2015). Within the field of environmental toxicology, SETAC fills this role, rallying professionals from academia, regulatory agencies, industry and NGOs through a commitment to interdisciplinary and multi-stakeholder dialogue. This commitment is enshrined in the society's by-laws, which guarantees equal representation from government, academia and industry, along with regional representation (SETAC 2014). Furthermore, its activities are animated by norms of scientific objectivity and a culture of civil discourse (SETAC North America (SNA) Board 2017 Feb 16; Menzie and Smith 2018). Given the prominence of SETAC and its specific ethos and norms, debates on NAMs at SETAC-organized events have the potential to influence what the larger

This article is protected by copyright. All rights reserved. 
REVISED - December 2019

environmental toxicology community knows about NAMs and how it evaluates their potential for regulatory adoption.

Concern for 'error cost' is a third potential factor affecting the perception of NAMs. This concept was first introduced by sociologists of science and technology, Collingridge and Reeves (1986). Using the concept, Montpetit (2011) argued that as emergent technology moves closer to application in policy, scientific disagreements become greater.

The error cost hypothesis: "The more a group of scientists becomes policy relevant, the more its knowledge will be scrutinized for potential errors and the more intensive the scrutiny, the higher the potential for disagreement among scientists.” (Montpetit 2011: 529)

Concerned that using scientific knowledge for policy decisions may yield negative consequences if they are wrong, scientists tend to 'double down' on scrutiny amongst themselves. This can have important implications for how NAMs are debated internally among the environmental toxicology research community, potentially heightening the scrutiny of testing approaches that deviate from established practice. Within the broader regulatory frameworks supporting environmental toxicology, standardized procedures designed to explicitly evaluate the remaining uncertainties when using results of NAMs and conventional techniques in risk assessment are considered important [see, for example, the European Food Safety Authority's Guidance on Uncertainty Analysis in Scientific Assessments (2018)].

Collaboration across stakeholders on NAMs (for example between end-users in government on the one hand and academic researchers on the other hand) is a fourth potential factor that may influence perceptions of their viability. The frequency of collaboration with different stakeholders (government, industry, academics, NGOs) may influence the nature and flow of information that different environmental toxicology professionals receive. In a context where NAMs are still emerging, and therefore present greater uncertainty than traditional testing methods, these different experiences with NAM-related information may create different perceptions.

Finally, paradigmatic beliefs (Kuhn 1962) - fundamental views on one's scientific discipline [e.g. what are the primary goals?; how can we reach significant conclusions?; what is important to study?] - may also influence perceptions of the viability of NAMs. By shaping the relative importance attached to information (i.e. raising or discounting the value of some information over another, paradigmatic beliefs can influence whether, how and what scientists learn about emergent technologies (Montpetit and Lachapelle 2015) such as NAMs.

\section{MATERIALS AND METHODS}

We surveyed members of the environmental toxicology community who had previously participated in at least one SETAC-organized event in order to assess their viewpoints on toxicity testing and their self-reported learning experiences at SETAC. Following the online survey research method (Dillman et al. 2008), we sought to better

This article is protected by copyright. All rights reserved. 
REVISED - December 2019

understand how the environmental toxicology community learns and adapts to emerging challenges.

\section{Survey instrument}

An initial version of our online survey instrument was pre-tested with seven members of the SETAC community in November 2017 to improve the clarity and logical flow of questions, and reduce the potential for bias. The survey instrument began with obtaining the informed consent of participants, followed by demographic questions related to the professional role and disciplinary training of the respondent. The next section of the survey sought to elicit the respondent's viewpoints on toxicity testing. We asked questions designed to elicit viewpoints related to the viability of alternative versus conventional testing strategies in environmental toxicology, adapted from previous surveys of professionals in the field of toxicology conducted by Zaunbrecher et al. (2017) and Vachon et al. (2017). According to the Cambridge dictionary, viability refers to the "ability to work as intended or to succeed". We therefore asked respondents their views on the ability of different NAMs to succeed/work in testing hazard. To answer this question we asked respondents to score NAMs on a scale that was previously developed by Zaunbrecher et al (2017) based on interviews with professionals in toxicology.

We also asked a series of questions requiring the respondent to rate their learning experiences and observations during SETAC-related activities (meetings, forums, working groups, conferences, networking events, etc.) on Likert-type scales. The survey was anonymous, was conducted with the permission of SETAC and received approval from the McGill University research ethics board. See Appendix 1 in Supplemental data for full questionnaire.

\section{Data collection}

Following a purposive sampling strategy, survey invitations were sent to members of SETAC between January and April 2018 using a combination of direct and indirect recruitment strategies, resulting in 171 completed responses (with an approximate response rate of 13\%). Direct survey invitations were sent to 1,300 SETAC members who were identified through SETAC interest groups, professional events and networks. The survey was also advertised through the SETAC Globe, an online publication distributed to $\sim 11,000$ subscribers, many of whom are not active SETAC members. Due to the open nature of our survey distribution strategy, the final response rate is unclear. However, considering there are over 5,000 SETAC members internationally, and that our sampling design was non-random, it is clear that our data does not permit us to generalize to the broader SETAC population (low external validity). Instead, the completed survey dataset provides a large purposive sample exhibiting a high degree of internal validity from which we can explore relationships and generate results that are appropriate for generalization to theory, based on the content and construct validity of our data collection instruments (following a case study logic, see (Yin 2003). We therefore present results in a descriptive rather than explanatory form and triangulate findings with other data sources, such as those presented in previous studies, the content of policy documentation

This article is protected by copyright. All rights reserved. 
REVISED - December 2019

and performance evaluations, and through our own participation in, and informal observation of, SETAC meetings, to help assess the reliability of our interpretation.

\section{Data analysis}

Throughout the analysis we paid special attention to differences in the perceptions of academics versus non-academics. The rationale for separating academic from nonacademic respondents was to explore whether different motivations for using NAMs influenced how respondents evaluated their viability. Arguably, academic respondents have less organizational pressures to be concerned about the policy application issues tied to using NAMs than individuals or groups associated with government or industry. The tradition of academic autonomy generally places them in a situation where the pursuit of knowledge for its own sake is the primary goal. This may influence academics' evaluation of the viability of NAMs.

We also used the survey data to develop ordered logistic regression (OLR) models in order to better understand the influence of exploratory variables on the probability of a respondent's categorical evaluation of the viability of different NAMs (dependent variable). Respondents' categorical evaluations or the relative ordering of evaluative responses are common in social and political science research, which are difficult analyze following the assumptions of common statistical techniques like Ordinary Least Square regression (Williams 2016). OLR is based on the cumulative probabilities of a dependent variable which is assumed to be a linear function of independent variables (Grilli and Rampichini 2014). OLR develops a series of cumulative logit models based on binary logistic regression. For example, this study initially performed a binary regression for the first two categories (i.e., category 0 versus category 1 ) of a NAM variable, while second binary regression involved categories 1 and 2 and so forth. In each binary model, the lower categories were coded as 0 and the higher category was considered as 1 . OLR model assumes that the coefficients of an independent variable in each binary logistic model are same - also known as a parallel assumption. An increase in the positive coefficient of an independent variable means a higher probability of support, while an increase in the negative coefficient of an independent variable means less support.

OLR is assumed to be based on the existence of a contentious and unobserved random $Y^{*}$ latent variable under the categorical dependent variable $Y$ (Yakut et al. 2015). The categories of $Y$ are measured as sequential intervals - also referred to as the threshold parameter - on a continuous plane (Kaplan and Prato 2012; Yakut et al. 2015). For $\alpha_{M-1}<$ $Y^{*}<\alpha_{M}$ and in any case between $\alpha=-\infty$ and $\alpha=+\infty, Y^{*}$ is expressed as (Yakut et al. 2015):

$$
Y_{i j}^{*}=\sum_{i=1}^{i} \beta_{i} X_{i}+\varepsilon
$$

The relation between observed $Y$ and unobserved $Y^{*}$ variables can be presented as:

This article is protected by copyright. All rights reserved. 
REVISED - December 2019

$$
Y_{i j}=\left\{\begin{array}{c}
0, \text { if }-\infty \leq Y_{i j}^{*}<\alpha_{1} \\
1, \text { if } \alpha_{1} \leq Y_{i j}^{*}<\alpha_{2} \\
2, \text { if } \alpha_{2} \leq Y_{i j}^{*}<\alpha_{3} \\
\vdots, \vdots \vdots \vdots \vdots \\
M, \text { if } \alpha_{M-1} \leq Y_{i j}^{*}<\alpha_{M}=\infty
\end{array}\right.
$$

Here, $j$ denotes different categories, $M$ is the number of categories, $\beta$ is the coefficient of an independent variable $X, \alpha$ is the threshold parameter of occurring a certain category.

The main independent variables were 1) cohort (year since last degree completed), 2) core scientific beliefs on environmental toxicology expressed by respondents' agreement with, among others, the Paracelsus adage ("the dose makes the poison") and the systems biology perspective ("all adverse outcomes originate from a molecular-level event"), and 3) the frequency of collaboration and exchange of information on alternative testing approaches with different stakeholders. Control variables included satisfaction with current toxicity testing methods used for decisionmaking, as well as self-reported level of knowledge on the NAM of interest. Before developing six OLR models (one for each NAM), we calculated Pearson correlation coefficients among the exploratory variables to identify if there was any strong positive or negative correlation among the exploratory variables. The results confirmed that the variables were not strongly correlated with $r< \pm 0.4$ for all the variable pairs, indicating an absence of autocorrelation in our data. Since the coefficients of independent variables are not often considered as reliable measures, we estimated the marginal effects of the exploratory variables to demonstrate the specific probability of each variable to influence the categorical responses with other variables held constant (see Appendix 3 in Supplemental data). We report individual p values for coefficients that were approaching statistical significance. Otherwise, the coefficients mentioned in the discussion are below the statistical significant thresholds (Table 2). To demonstrate the goodness-of-fit of the models, we took account of several measures: i) maximum log-likelihood with an assumption that the lower the value, the better a model fits; ii) McFadden's $\mathrm{R}^{2}$, also known as a pseudo $\mathrm{R}^{2}$, the higher value of which indicates better model fit; and iii) Akaike information criterion (AIC), whose lower value indicates better model fit.

\section{RESULTS AND DISCUSSION}

Consistent with SETAC membership, the majority of our sample was comprised of academics (Table 1). Reflecting that SETAC is a global organization, our sample was distributed across five continents, with the greatest number of respondents based in Europe (36\%).

\section{$<<$ INSERT TABLE 1 ABOUT HERE $>>$}

Interestingly, 70\% of respondents (120/171) reported not being satisfied with the way that ecological toxicity testing is currently carried out for regulatory purposes in their jurisdiction. This finding supports the relevance of our study and is in line with the

This article is protected by copyright. All rights reserved. 
REVISED - December 2019

ongoing discourse in the environmental toxicology community concerning the need for alternative testing methods to respond to current challenges.

\section{How NAMs are discussed}

We asked respondents to observe how frequently the scientific grounds of NAMs are challenged at SETAC-organized events compared to conventional testing methods (Figure 1).

\section{$<<$ INSERT FIGURE 1 ABOUT HERE $>>$}

The perception of respondents was that NAMs are systematically challenged more frequently than conventional testing methods during SETAC activities (Figure 1). In other words, studies using NAMs were regularly subjected to more methodological critique and contestation than studies using conventional testing methods at SETAC events. This finding resonates with existing research suggesting that NAMs are submitted to stricter validation criteria than animal tests (Balls and Fentem 1997). It is also consistent with the error cost hypothesis. Research that has found alternative testing methods to lack reliability for use in legal settings (Bergeson 2008) and highlighted actors' concern with litigation from retrospective analysis of alternative test data (Pettit et al. 2010) indicates that error cost impacts the validation and adoption of NAMs. As new standards and policies increasingly consider NAMs for inclusion, Montpetit's (2011) error cost hypothesis suggests further criticism and debate within the environmental toxicology community.

Our findings also suggest that scientific debates of toxicity testing methods at SETAC-organized events are, overall, balanced. On average, respondents reported that although NAMs were more frequently challenged than conventional testing methods, both testing methods were challenged at a frequency level that is near the mid-point of the 5 point scale (Figure 1). Furthermore, 35\% of respondents reported that SETAC discussions on the policy consequences of using alternative testing strategies were 'balanced', compared to respondents that reported discussions tended to focus on 'negative' (8\%) or 'positive' (18\%) policy consequences (39\% did not know; results not shown in figures).

We also explored the extent to which discussions about toxicity testing at SETAC differed from the respondent's experience in their wider professional work environment. The skewness values indicated that respondents felt that discussions of gaps in toxicity testing at SETAC were on average slightly more open than similar discussions in their workplace (Figure 2). However, the distribution and mean for the two questions were not substantially different. These findings indicate that NAMs are discussed in similar ways at SETAC and in the workplace. More broadly, structural barriers to communication stemming from the separation of environmental toxicology into disciplines and sectors which SETAC seeks to overcome through its principles of multidisciplinary problem solving and balanced participation from all sectors (SETAC 2019) - may affect NAM discussions and adoption among SETAC members and possibly the environmental toxicology community altogether.

This article is protected by copyright. All rights reserved. 
REVISED - December 2019

$<<$ INSERT FIGURE 2 ABOUT HERE $>>$

\section{Viability of NAMs}

NAMs were defined as follows: 1) In silico approaches (e.g. (Q)SARs, physiological toxicokinetic modeling); 2) In vitro testing (e.g. cell-based, cell-free or biochemical assays); 3) In vivo early life stage (ELS) testing (e.g. whole animal exposures prior to independent feeding); 4) Omics approaches (e.g. genomics, transcriptomics, metabolomics, proteomics); 5) High throughput screening. How did respondents evaluate the viability of different NAMs? The mean scores for five different NAM classes, showing the means for all respondents, as well as for sub-samples of academic respondents and non-academic respondents are shown in Figure 3.

\section{$<<$ INSERT FIGURE 3 ABOUT HERE $>>$}

Analysis of the results show that, on average, respondents thought that NAMs were generally nearing the point of being viable (i.e., in most cases, within 5 years) (Figure 3). As a comparative benchmark, 90\% of respondents found conventional methods viable and 8\% found them 'not viable', and 2\% 'did not know' (our survey data, not shown in figures). The order (from more to less viable) in which the different NAMs appeared broadly reflects their respective introductions into the toxicity testing community, suggesting that familiarity influenced perceptions of viability. On average, respondents perceived early life stage testing as closest to being viable relative to the other NAMs, and they did so with less variation (lowest overall standard deviation). This likely reflects a pattern of higher familiarity given that many regulatory tests already allow for ELS, confirming what we would expect. Similarly, it is commonly accepted that, with few exceptions, ELS are considered the most vulnerable and sensitive life stage of most organisms.

Within specific NAM categories some notable contrasts emerged in their mean ranking based on different employer categories. Non-academics, on average, reported that in silico approaches would be viable sooner than the timeframe reported by academics. Conversely, academics, on average, reported 'omics approaches as becoming viable sooner than non-academics. These differences between academics and nonacademics were statistically significant. We recognize that the professional background of academics (e.g. modelers versus experimenters) may also be important to these results, however we were unable to test this with our data.

The reported difference between academics and non-academics for in silico approaches may also be driven by the existence of regulations and guidelines. Quantitative Structure-Activity Relationship (QSAR) models are being increasingly used by industry, and governments in Europe (ECHA 2016b: 69). In North America, industry and regulatory agencies have long used QSAR models for hazard identifications and other applications. For example, QSAR predictions are one of many potential sources of data for weight-of-evidence (WoE) approaches to the risk assessment of pesticides (U.S. EPA 2012). In the pharmaceutical industry, QSAR modeling has been used traditionally for lead optimization - the process by which a drug candidate is designed after an initial

This article is protected by copyright. All rights reserved. 


\section{REVISED - December 2019}

lead compound is identified. Recently, industry has used QSAR modeling to discover lead compounds, predict drug-like properties of compounds, and chemical risk assessment (Golbraikh et al. 2017). Regulators have made similar advances: the OECD has been involved in extending the use of "read-across" for at least a decade, notably through its QSAR toolbox (Read-across is an alternative approach for predicting endpoint information for target substance(s) by using existing data for the same endpoint from other substance(s)). Related to familiarity, Paterson and Whelan (2017) suggested that determining the value of QSAR models is a "process of social epistemology" between end-user and modeler. In chemical risk assessment, QSAR models essentially provide decision-making value as a heuristic, i.e. a guide grounded in practical conditions that although not methodologically optimal, may nonetheless help regulatory scientists make substantiated judgment calls based on WoE. There are, however, challenges involved in using models due to their complexity and the limited number of people that can delve into their specifics. As Paterson and Whelan (2017: 14) explain: "Some computational models of biological systems would appear to be untestable due to their complexity and the difficulty in acquiring reliable data from the biological system. It is tempting at this point, to trust the judgment of the modeler and accept that the simulation will provide interesting information." Accepting such a trade-off between a methodologically suboptimal, but nonetheless practical, model may deter academics. Arguably, academics are generally less prone to 'trust the modeler' and will want to 'see what's under the hood' (if they have the necessary knowledge) before endorsing a method or study. These dynamics mirror similar "operability vs scientific rigor" debates that occurred between attributional life-cycle analysis and consequential life-cycle analysis in biofuel standard-setting discussions (Winickoff and Mondou 2017: 23).

Why did our sample of academics and government professionals on average respond that 'omics approaches were closer to being viable than other stakeholders? Fueled by government-funded initiatives, 'omics-based approaches have gathered considerable momentum in the academic community over the last 10 years following the publication of "Toxicity testing in the $21^{\text {st }}$ century" (National Research Council 2007). For example, the number of scientific papers citing toxicogenomics has increased exponentially since 2007 (Mittal 2018), indicating that researchers that publish in academic journals have embraced the new possibilities that 'omics offers toxicity testing. The systems biology and mode of action (MoA) perspectives that underpin 'omics-based approaches likely also feed academic curiosity to better understand the complexity of biological systems. In this sense, academics may be more inclined to favor 'omics to help understand hazard. In contrast, this complexity may have a negative effect on respondents that are more concerned about the difficulties of making consistent, predictable and explainable 'omics-based regulatory determinations. The uncertainty and complexity innate to 'omics-based approaches (non-monotonic dose responses, compensatory feedback loops, etc.) collides directly with norms of procedural fairness (using the same standards of decision-making for each applicant or each substance) that bureaucracies and courts use to uphold regulatory determinations on what is a defensible toxicity threshold (Bergeson 2008; Pettit et al. 2010). As a result, business respondents - while applying omics tools to study the potentially adverse effects of pharmaceutical drugs, and industrial and environmental chemicals (Balbus and Environmental Defense 2005;

This article is protected by copyright. All rights reserved. 
REVISED - December 2019

ECETOC 2007) - may declare 'omics approaches less viable, consistent with our findings (Figure 3). In other words, industry's concern for regulatory risk may influence their perception of the viability of 'omics-based approaches. At the same time, government respondents generally viewed 'omics approaches as more viable than the sample average. This may reflect some of the initial momentum of 'omics approaches being championed by government agencies (Shostak 2005), however further research in order to better understand how different contexts might affect this pattern would be useful.

Interestingly, all of the 21 respondents from business answered that in vitro methods 'May be viable within 5 to 10 years', while the mean values reported by respondents from other employer categories were near the mid-point between 'Viable' and 'May be viable within 1 to 5 years'. Although caution needs to be exercised when interpreting such a small subsample of respondents $(n=21)$, the contrast as well as the unanimity in response was striking.

\section{Factors affecting the perception of NAMs}

To further examine the potential factors affecting the perceptions of respondents related to the viability of NAMs, we built ordered logistic regression models (Table 2). There were 6 models (columns), one per test method. Response variables included the perceptions concerning the viability of the different methods for testing hazard. Three blocks of exploratory variables -1) professional profile; 2) paradigmatic beliefs about environmental toxicology; and 3) frequency of collaboration with different stakeholders were included in the models (Table 2). Control variables included satisfaction with regulatory testing and knowledge levels regarding the given test methods. For ordered logistic regressions, the direction of the probabilistic relationships were interpretable (i.e., positive vs negative), but not the strength of the probabilities. Online supplemental data contain the marginal effects tables (Appendix 3), which allow the reader to interpret more fully the probability of an exploratory variable influencing the change in response variable for each outcome value of the response variable.

$<<$ INSERT TABLE 2 ABOUT HERE $>>$

With regard to professional profile, the results supported the hypothesis that cohort has a potential influence on perceptions of test method viability. Less recent graduates had a lower probability of perceiving in silico and 'omics-based approaches $(p=0.168)$ as closer to being viable than more recent graduates. Additionally, less recent graduates had a higher probability of perceiving conventional testing as being viable than more recent graduates. The social mechanism behind this relationship may be associated with changes in the educational curriculum in relevant degree programs. Given that NAMs are often developed in academic research environments, their content is likely initially diffused by academics through their teaching. Plotting the relationship between years since last degree and viability shows that there is a great deal of variation within outcome values, which suggests that while the correlation for 'omics, in silico, and conventional, is significant, it is also weak (see Appendix 4 in supplemental data). Results for the academics vs non-academics variable were less clear-cut, with only a

This article is protected by copyright. All rights reserved. 
positive relationship with in silico methods being statistically significant. Both results are consistent with the interpretation that familiarity is an important factor influencing perceptions of viability.

Results for the second set of exploratory variables provide little support to the hypothesis that paradigmatic beliefs about environmental toxicology influence perceptions of NAM viability. We asked several questions eliciting respondents' viewpoints on environmental toxicology (e.g. "Whole animal studies are the best way to understand the integrated way in which biological systems work", "The maxim 'the dose makes the poison' is an accurate guide for testing all chemicals”, "All adverse outcomes originate from a molecular-level event”). For ease of interpretation, we inverted some of the scales for these questions to create a consistent pattern where agreement with the statement was consistent with status quo opinions in environmental toxicology. Therefore, the theoretical expectation was a negative relationship for the NAM models and a positive relationship for the conventional testing model. Of a total of 24 relationships explained in all the models, 12 (50\%) indicated a direction that was consistent with this theoretical expectation. Out of 3 statistically significant relationships $(\mathrm{p}<0.1), 3$ indicated a direction that was consistent with theoretical expectation. Interestingly, there was a statistically significant positive relationship between agreement with the Paracelsus maxim and perceptions of viability for conventional testing (i.e. respondents who agreed with the Paracelsus maxim had a greater likelihood of finding conventional testing viable, and inversely, respondents who disagreed with the Paracelsus maxim had a greater likelihood of finding conventional testing not viable). Although caution needs to be exercised when interpreting the meaning of a single coefficient in the model, this correlation is of interest given the debate on non-monotonic responses in endocrinology. Such responses challenge the Paracelsus maxim, with the "Dietrich v. Gore" letters (Dietrich et al. 2013; Gore et al. 2013) showing how deep the divide between these schools of thought is (Cressey 2013). Respondents' evaluation of the "dose makes the poison" question can be considered an approximation of whether respondents accept the endocrine disruption hypothesis and the relevance of 'low dose effects' to chemical risk assessment. Relatedly, the distribution of responses to the Paracelsus question was bimodal, suggesting that our sample reflected disagreements on the existence of non-monotonic dose-response curves. While these data suggest that paradigmatic beliefs on environmental toxicology are not significantly important factors in determining perceptions of test viability, it remains to be seen if these beliefs affect the process of learning about NAMs.

Results for the third set of exploratory variables were related to the frequency of collaboration with different stakeholders, and these showed variable responses. There was one clear pattern, however: the more a respondent reported collaborating/exchanging information with industry on alternative testing strategies, the more likely she/he was to report that 'omics-based approaches, in vitro, in silico and high-throughput screening were less close to being viable. There was also a statistically significant positive relationship between reported frequency of collaboration with consultants and reported perception of viability of in silico and early life-stage tests, and a statistically significant

This article is protected by copyright. All rights reserved. 
REVISED - December 2019

positive relationship between collaboration with NGOs and perception of the viability of 'omics and high-throughput screening approaches.

With regards to the knowledge levels, the results generally aligned with expectations (with 'omics at $\mathrm{p}=0.171$ ). The findings demonstrated strong support for the expectation that the more knowledgeable an individual was regarding a given test method, the more she/he found such a test method viable, again reinforcing the 'pattern of familiarity' interpretation.

\section{INSIGHTS FOR THE IMPROVEMENT OF ENVIRONMENTAL REGULATION}

Broadly, the finding that NAMs are more likely to be critiqued and challenged than conventional testing in professional forum discussions suggests that change in regulatory science is subject to a dynamic of social interaction, both democratic and technical, that slows its pace. In this particular dynamic, concern for 'error costs' could be an important mechanism slowing policy experimentation with, and adoption of, potentially viable NAMs. As Montpetit (2011: 520) discussed: "When policymakers turn to a scientific community for policy advice, the cost of their potential errors suddenly increases. (...) Therefore, questioning the science behind the advice and expanding the debate to unattended questions becomes the reasonable thing to do." In a policy context, where science is already a purveyor of advice according to conventional forms, the potential errors that environmental management professionals make by using conventional methods are more familiar. Therefore, such errors can be justified within 'tried and tested' bounds of professional judgment calls related to uncertainty. However, such professional 'immunity' does not exist for new regulatory science, creating asymmetric options akin to free solo climbing vs. harnessed climbing.

Another way of reconciling this finding is to attribute heightened scrutiny to the fact that NAMs are now in the implementation stage of policy-making (ECHA 2014; ECHA 2016a; Environment and Climate Change Canada 2016; ICCVAM 2018; U.S. EPA 2018). In her book "Science in Environmental Policy - The Politics of Objective Advice”, Ann Keller (2009) observed that scientists' influence decreases as the policy process moves from agenda-setting (recognizing an issue as an important public problem) to implementation. Case studies of acid rain and climate change policies in the US led her to conclude that it was not the strength of the science that explained policy influence: "As the policy process unfolds, scientists are placed under increasing scrutiny with respect to the credibility of the advice they offer, even as scientific uncertainties are reduced" (Keller 2009: 170). As new science translates into operationalized regulatory science, scientists often become increasingly concerned with being seen as exceeding their mandate. This social and reputational dynamic, along with concern for 'error cost', generate inertia in regulatory science. They are processes that exert pressure towards the perpetuation of status quo in regulatory science.

At the same time, our findings show that the acceptance of NAMs is relatively close to the level for conventional methods in our sample of respondents. It may be that increased scrutiny for NAMs compared to conventional methods is progressively evening

This article is protected by copyright. All rights reserved. 
out, as the "decades long process" of adopting NAMs is proceeding (National Research Council 2007: 16; Zaunbrecher et al. 2017).

How can we avoid prolonging this process further? One clear path is to increase the environmental toxicology community's familiarity with NAMs. Our findings related to the cohort effect and 'pattern of familiarity' - which correspond with those of Zaunbrecher et al. (2017) - and those related to collaboration patterns support the view that the pace of change in environmental regulatory science is in no small part influenced by how and when content in a given scientific specialty is diffused/transmitted. If perceptions of the viability of a given method to make regulatory determinations vary according to cohort, collaboration patterns across stakeholders and knowledge level on the given method, then acceptance of that test method is not only a scientific process of knowledge communication. It is also a social learning process that could, for example, involve redefining curriculum and continued learning initiatives. Making a given piece of regulatory science familiar implies that professional practice in that area is regularly confronted with its use in their work setting.

Another path could be to "open the floodgates" and think about innovative ways to make decisions with new forms of uncertainty and complexity. Regulatory agencies do not have prescribed procedures to manage non-monotonic dose responses, compensatory feedback loops and other forms of novel uncertainty. This does not mean that these emergent scientific concepts are not useful to regulation, but rather that regulatory innovation is needed. Consistent with our findings on collaboration patterns, one way to promote innovation in regulatory science will be diversifying the patterns of information transmission across (potentially new) stakeholders.

\section{CONCLUSION}

In a recent commentary, SETAC leadership reaffirmed its commitment to the multidisciplinary and multi-sectorial credo of the society as the bulwark against partisanship and the best approach to "distilling the [scientific] essence of the matter" (Menzie and Smith 2018). Interestingly, the authors mention that this credo is based on recognition that "bias is pervasive" and that we "can't escape it, but we can acknowledge and manage it." In this article, we have empirically examined and discussed sources of bias that may not have been fully acknowledged within the environmental toxicology community. Our findings suggest that there are sources of bias that are constitutive of scientific discourse itself, and usefully complement existing reflections on how to approach the science-policy interface in the environmental toxicology community, such as the ideas captured in the "Late Lessons from Early Warnings: science, precaution, innovation” report (European Environment Agency 2013). We have contributed to showing that social processes can shorten or lengthen the now decades long process of adopting NAMs: specifically increased scrutiny fuelled by the 'politics of objective advice' and concern for 'error cost', patterns of transmission of knowledge (cohort and familiarity) and information between professionals.

This article is protected by copyright. All rights reserved. 
REVISED - December 2019

\section{CAPTIONS}

Figure 1:

"How often have you observed the following during SETAC activities?", mean of a 5 point Likert scale; error bars represent standard error of the mean, $n=171$

Note: * Differences between alternative and conventional testing method are all statistically significant (alpha= 0.05; two-tailed Mann-Whitney U test). See Supplemental material for more detail.

Note: $0=$ Never, $4=$ Very often

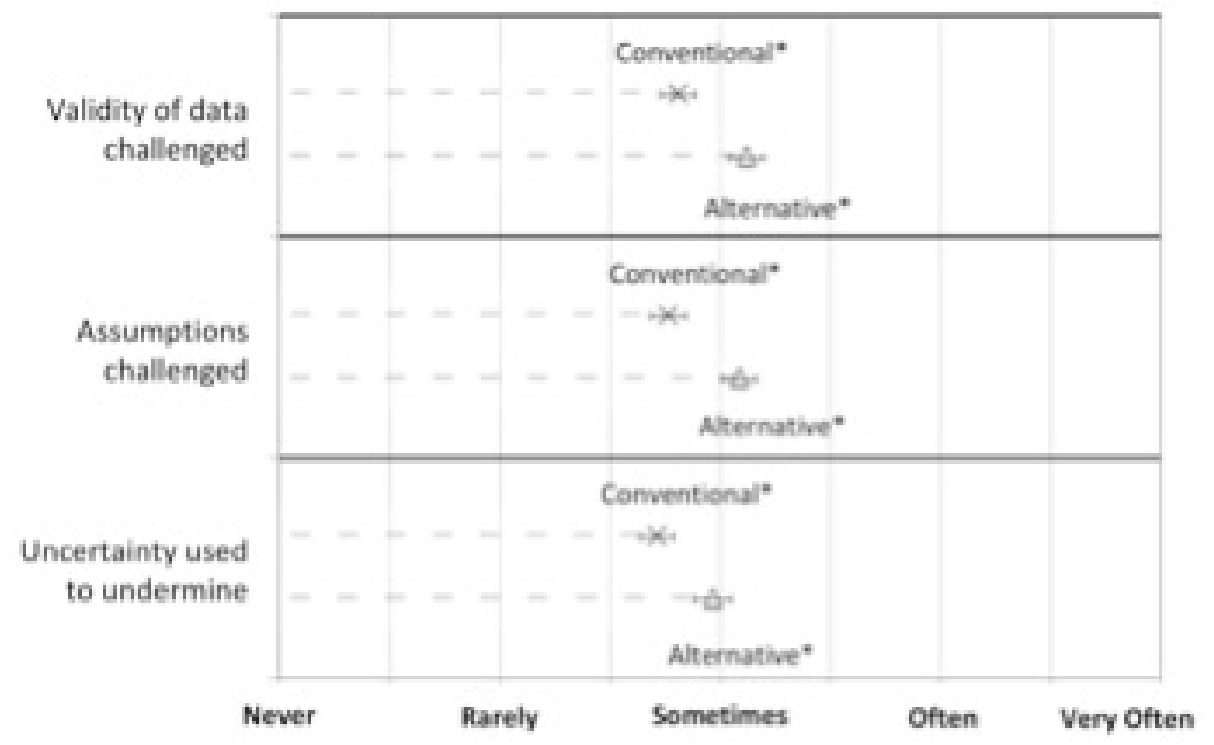

This article is protected by copyright. All rights reserved. 
REVISED - December 2019

Figure 2:

"To what extent do you agree or disagree with the following statements?", distribution of a 5 point Likert scale, $n=171$

Note: -2 = Strongly Disagree, $+2=$ Strongly Agree

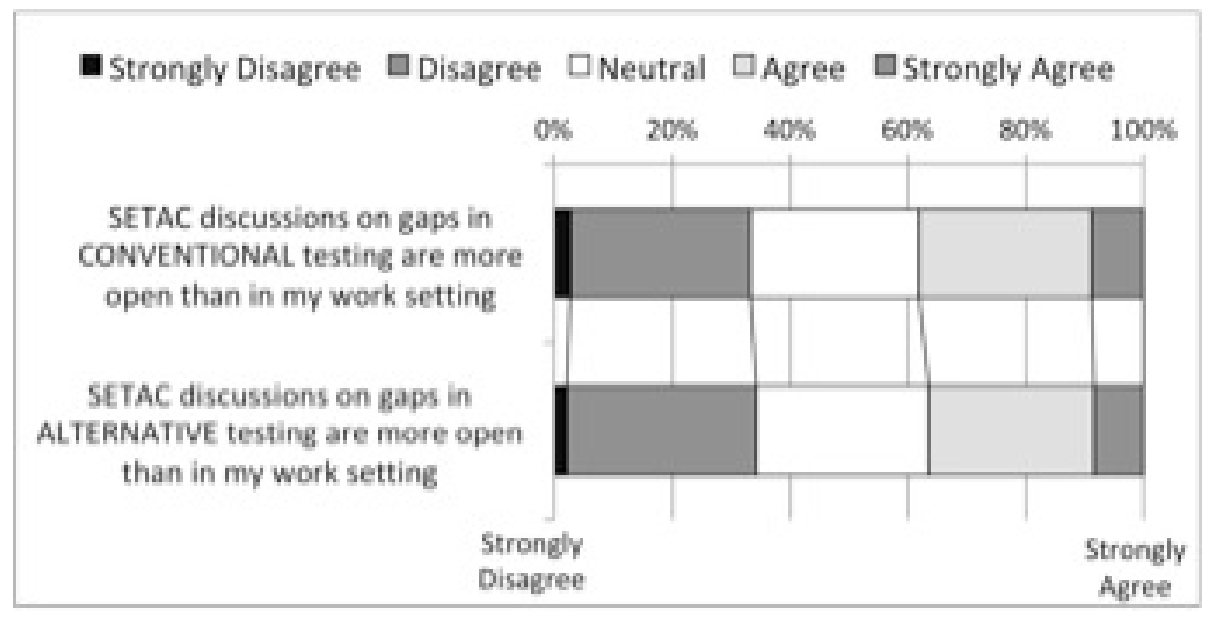

Figure 3:

"To what extent do you believe the following alternative approaches are viable for testing hazard?" mean of a scale 0 to 3 , error bars are standard error of the mean; $n$ for academics $=95, n$ for non-academics $=71, n$ for all $=171$

Note: * indicates differences between academics and non-academics are statistically significant (alpha= 0.05; two-tailed Mann-Whitney U test).

Note: Range of values: 0 to 3; standard deviation between parenthesis.

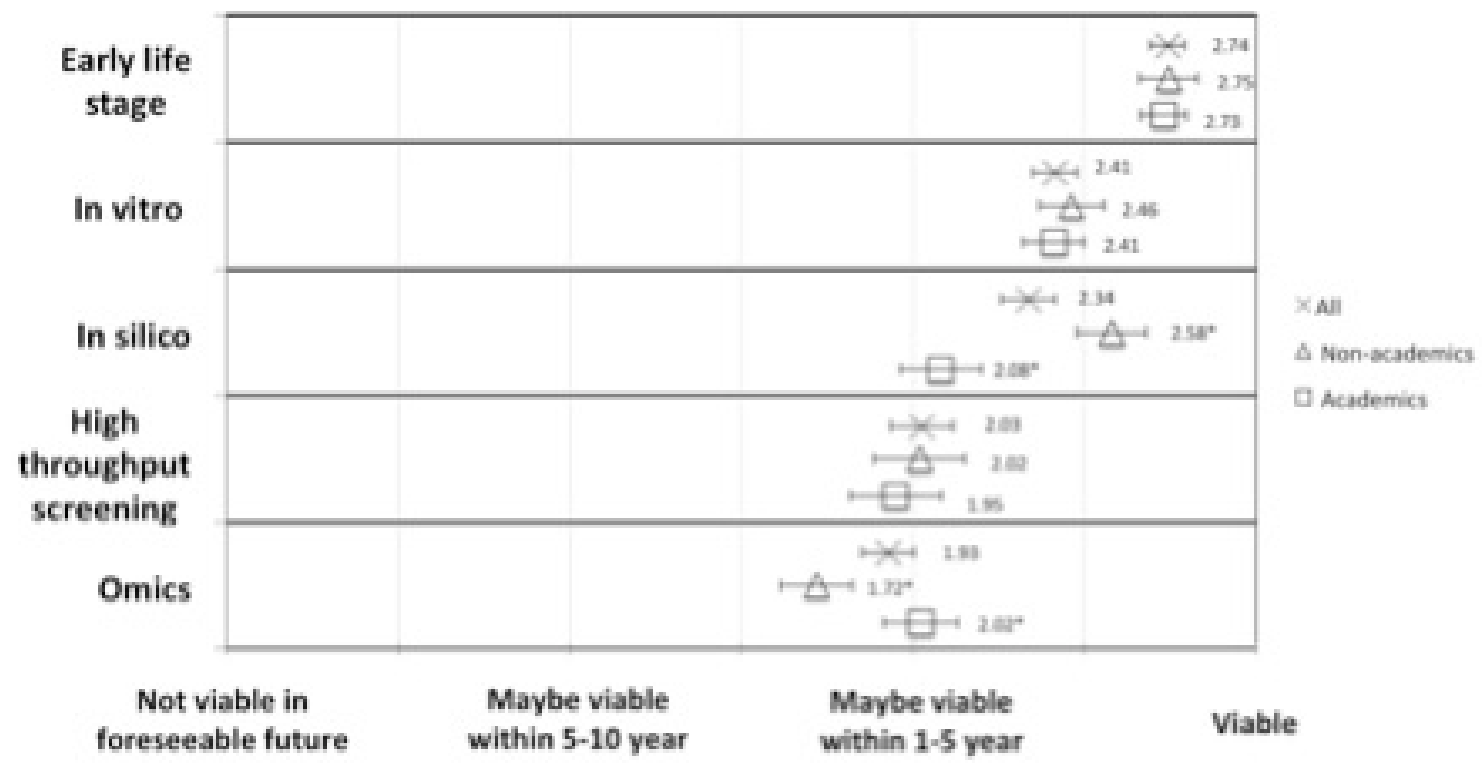

This article is protected by copyright. All rights reserved. 
REVISED - December 2019

\section{WORKS CITED}

Ankley G, Daston G, Degitz SJ, Denslow ND, Hoke RA, Kennedy SW, Miracle AL, Perkins EJ, Snape J, Tillitt DE, et al. 2006. Toxicogenomics in Regulatory Ecotoxicology. Environ Sci Technol. 40(13):4055-4065.

Arnold C. 2015. ToxCast ${ }^{\mathrm{TM}}$ Wants You: Recommendations for Engaging the Broader Scientific Community. Environ Health Perspect. 123(1):A20-A20. doi:10.1289/ehp.123A20.

Balbus JM, Environmental Defense. 2005. Toxicogenomics: harnessing the power of new technology. New York, NY: Environmental Defense.

Balls M, Fentem JH. 1997. Progress Toward the Validation of Alternative Tests. Altern Lab Anim.(25):33-43.

Basu N, Crump D, Head J, Hickey G, Hogan N, Maguire S, Xia J, Hecker M. 2019. EcoToxChip: A next-generation toxicogenomics tool for chemical prioritization and environmental management. Environ Toxicol Chem. 38(2):279-288. doi:10.1002/etc.4309.

Bergeson LL. 2008. Challenges in Applying Toxicogenomic Data in Federal Regulatory Settings. In: Genomics and Environmental Regulation: Science, Ethics, and Law. Baltimore: Johns Hopkins University Press. p. 67. [accessed 2017 Jun 19]. https://muse.jhu.edu/book/3343.

Bradbury SP, Feijtel TCJ, Leeuwen CJV. 2004. Meeting the Scientific Needs of Ecological Risk Assessment in a Regulatory Context. Environ Sci Technol. 38(23):463A470A. doi:10.1021/es040675s.

Busquet F, Hartung T. 2017. The need for strategic development of safety sciences. Altern Anim Exp ALTEX. 34(1):3-21.

Collingridge D, Reeve C. 1986. Science Speaks to Power: The Role of Experts in Policy Making. London: Frances Pinter.

Council of Canadian Academies. 2012. Integrating emerging technologies into chemical safety assessment. Ottawa: Council of Canadian Academies. [accessed 2018 Aug 7]. http://www.deslibris.ca/ID/231723.

Cressey D. 2013. Journal editors trade blows over toxicology. Nat News. doi:10.1038/nature.2013.13787. [accessed 2018 Sep 11]. http://www.nature.com/news/journal-editors-trade-blows-over-toxicology-1.13787.

Dietrich D, von Aulock S, Marquardt HWJ, Blaauboer BJ, Dekant W, Kehrer J, Hengstler JG, Collier AC, Gori GB, Pelkonen O, et al. 2013. Open letter to the European commission: scientifically unfounded precaution drives European commission's recommendations on EDC regulation, while defying common sense, well-established

This article is protected by copyright. All rights reserved. 
REVISED - December 2019

science, and risk assessment principles. Arch Toxicol. 87(9):1739-1741.

doi:10.1007/s00204-013-1117-2.

Dillman DA, Smyth JD, Christian LM. 2008. Internet, Mail, and Mixed-Mode Surveys:

The Tailored Design Method. 3 edition. Hoboken, N.J: Wiley.

ECETOC. 2007. Workshop on the Application of 'Omic Technologies in Toxicology and Ecotoxicology: Case Studies and Risk Assessment, 6-7 December 2007, Malaga.

Brussels, July 2008 Workshop report No. 11. [accessed 2017 Nov 29]. http://www.ecetoc.org/wp-content/uploads/2014/08/ECETOC-WR-11-Application-of\%E2\%80\%98Omic-Technologies-in-Tox-Ecotox.pdf.

ECHA. 2014. The Use of Alternatives to Testing on Animals for the REACH Regulation. Helsinki: ECHA. [accessed 2017 Sep 25].

https://echa.europa.eu/documents/10162/13639/alternatives_test_animals_2014_en.pdf/5 87d000c-688e-4cdd-9f59-f7d7aacc677b.

ECHA. 2016a. New Approach Methodologies in Regulatory Science - Proceedings of a scientific workshop. Helsinki, Finland: ECHA. [accessed 2017 Sep 25].

https://echa.europa.eu/documents/10162/22816069/scientific_ws_proceedings_en.pdf/a2 087434-0407-4705-9057-95d9c2c2cc57.

ECHA. 2016b. Report on the Operation of REACH and CLP 2016. Helsinki: ECHA. [accessed 2017 Sep 25].

https://echa.europa.eu/documents/10162/13634/operation_reach_clp_2016_en.pdf/4c958 d7a-3158-447b-9e81-d8bae9a7e7f9.

EFSA Scientific Committee, Benford D, Halldorsson T, Jeger MJ, Knutsen HK, More S, Naegeli H, Noteborn H, Ockleford C, Ricci A, et al. 2018. Guidance on Uncertainty Analysis in Scientific Assessments. EFSA J. 16(1). doi:10.2903/j.efsa.2018.5123. [accessed 2019 Dec 6]. http://doi.wiley.com/10.2903/j.efsa.2018.5123.

Environment and Climate Change Canada. 2016. Integrating New Approach Methodologies within the CMP: Identifying Priorities for Risk Assessment, Existing Substances Risk Assessment Program. Ottawa: Government of Canada. [accessed 2017 Aug 15]. http://www.ec.gc.ca/ese-ees/default.asp?lang=En\&n=172614CE-1.

European Environment Agency, editor. 2013. Late lessons from early warnings: science, precaution, innovation. Copenhagen: European Environment Agency (EEA report).

Fischer M, Leifeld P. 2015. Policy forums: Why do they exist and what are they used for? Policy Sci. 48(3):363-382. doi:10.1007/s11077-015-9224-y.

Freeman K. 2004. Toxicogenomics data: the road to acceptance. Environ Health Perspect. 112(12):A678.

Golbraikh A, Wang XS, Zhu H, Tropsha A. 2017. Predictive QSAR Modeling: Methods and Applications in Drug Discovery and Chemical Risk Assessment. In: Leszczynski J,

This article is protected by copyright. All rights reserved. 
REVISED - December 2019

Kaczmarek-Kędziera A, Puzyn T, Papadopulos MG, Reis H, Shukla M, editors. Handbook of computational chemistry. Second edition. Cham: Springer. p. 2303-2340.

Gore AC, Balthazart J, Bikle D, Carpenter DO, Crews D, Czernichow P, DiamantiKandarakis E, Dores RM, Grattan D, Hof PR, et al. 2013. Policy Decisions on Endocrine Disruptors Should Be Based on Science Across Disciplines: A Response to Dietrich et al. Endocrinology. 154(11):3957-3960. doi:10.1210/en.2013-1854.

Grilli L, Rampichini C. 2014. Ordered Logit Model. In: Michalos AC, editor. Encyclopedia of Quality of Life and Well-Being Research. Dordrecht: Springer Netherlands. p. 4510-4513. https://doi.org/10.1007/978-94-007-0753-5_2023.

Hartung T. 2011. From alternative methods to a new toxicology. Eur J Pharm Biopharm. 77(3):338-349. doi:10.1016/j.ejpb.2010.12.027.

ICCVAM. 2018. A Strategic Roadmap for Establishing New Approaches to Evaluate the Safety of Chemicals and Medical Products in the United States. [accessed 2018 Jan 31]. https://ntp.niehs.nih.gov/iccvam/docs/roadmap/iccvam_strategicroadmap_january2018_d ocument_508.pdf.

Kaplan S, Prato CG. 2012. Risk factors associated with bus accident severity in the United States: A generalized ordered logit model. J Safety Res. 43(3):171-180.

doi:10.1016/j.jsr.2012.05.003.

Kavlock RJ, Bahadori T, Barton-Maclaren TS, Gwinn MR, Rasenberg M, Thomas RS. 2018. Accelerating the Pace of Chemical Risk Assessment. Chem Res Toxicol. 31(5):287-290. doi:10.1021/acs.chemrestox.7b00339.

Keller AC. 2009. Science in Environmental Policy: The Politics of Objective Advice. The MIT Press. [accessed 2018 Aug 23].

http://mitpress.universitypressscholarship.com/view/10.7551/mitpress/9780262013123.0 01.0001/upso-9780262013123.

Krewski D, Jr DA, Andersen M, Anderson H, III JCB, Boekelheide K, Brent R, Charnley G, Cheung VG, Jr SG, et al. 2010. Toxicity Testing in the 21st Century: A Vision and a Strategy. J Toxicol Environ Health Part B. 13(2-4):51-138.

doi:10.1080/10937404.2010.483176.

Kuhn TS. 1962. The structure of scientific revolutions. [2d ed., enl. Chicago: University of Chicago Press (International encyclopedia of unified science. Foundations of the unity of science, v. 2, no. 2).

Martin MT, Knudsen TB, Judson RS, Kavlock RJ, Dix DJ. 2012. Economic benefits of using adaptive predictive models of reproductive toxicity in the context of a tiered testing program. Syst Biol Reprod Med. 58(1):3-9. doi:10.3109/19396368.2011.652288.

This article is protected by copyright. All rights reserved. 
REVISED - December 2019

Menzie C, Smith R. 2018. Scientific Integrity Must Rise Above Partisanship. SETAC Globe. 19(8). [accessed 2018 Sep 6]. https://globe.setac.org/scientific-integrity-must-riseabove-partisanship/.

Mittal K. 2018. The Use of Traditional and Alternative Methods to Study Endocrine Disruption in Model Avian Species. [Montreal]: McGill University.

Montpetit É. 2011. Scientific Credibility, Disagreement, and Error Costs in 17 Biotechnology Policy Subsystems. Policy Stud J. 39(3):513-533.

Montpetit É, Lachapelle E. 2015. Information, values and expert decision-making: the case of soil decontamination. Policy Sci. 49(2):155-171.

National Research Council. 2007. Toxicity Testing in the 21st Century: A Vision and a Strategy. Washington, D.C.: National Academies Press. [accessed 2017 Jun 19]. http://www.nap.edu/catalog/11970.

National Toxicology Program. 2004. A National Toxicology Program for the 21st Century -- A Roadmap for the Future. Research Triangle Park, NC: National Toxicology Program (NTP).

Patterson EA, Whelan MP. 2017. A framework to establish credibility of computational models in biology. Prog Biophys Mol Biol. 129:13-19.

doi:10.1016/j.pbiomolbio.2016.08.007.

Pettit S, des Etages SA, Mylecraine L, Snyder R, Fostel J, Dunn RT, Haymes K, Duval M, Stevens J, Afshari C, et al. 2010. Current and Future Applications of Toxicogenomics: Results Summary of a Survey from the HESI Genomics State of Science Subcommittee. Environ Health Perspect. 118(7):992-997. doi:10.1289/ehp.0901501.

Sauer UG, Deferme L, Gribaldo L, Hackermüller J, Tralau T, van Ravenzwaay B, Yauk C, Poole A, Tong W, Gant TW. 2017 Sep. The challenge of the application of'omics technologies in chemicals risk assessment: Background and outlook. Regul Toxicol Pharmacol. doi:10.1016/j.yrtph.2017.09.020. [accessed 2017 Dec 11]. http://linkinghub.elsevier.com/retrieve/pii/S0273230017302921.

SETAC. 2014. SETAC by-laws. https://www.setac.org/resource/resmgr/About_SETAC/SETAC_BYLAWS_Revision_22 _Dec.pdf.

SETAC. 2019. SETAC’s Mission - Society of Environmental Toxicology and Chemistry. SETAC. [accessed 2019 Nov 8]. https://www.setac.org/page/Mission.

SETAC North America (SNA) Board. 2017 Feb 16. SETAC Provides a Shared Set of Core Values - Society of Environmental Toxicology and Chemistry. [accessed 2017 Nov 19]. https://www.setac.org/news/news.asp?id=331698.

This article is protected by copyright. All rights reserved. 
REVISED - December 2019

Shostak S. 2005. The Emergence of Toxicogenomics: A Case Study of Molecularization. Soc Stud Sci. 35(3):367-403. doi:10.1177/0306312705049882.

Standing Committee on Emerging Science for Environmental Health Decisions, Board on Life Sciences, Board on Environmental Studies and Toxicology, Division on Earth and Life Studies, National Academies of Sciences, Engineering, and Medicine. 2018. Understanding Pathways to a Paradigm Shift in Toxicity Testing and Decision-Making: Proceedings of a Workshop in Brief. Fitzpatrick J, editor. Washington, D.C.: National Academies Press. [accessed 2018 Jun 1]. https://www.nap.edu/catalog/25135.

Tickner J, Jacobs M, Malloy T, Buck T, Stone A, Blake A, Edwards S. 2018. Advancing Alternatives Assessment for Safer Chemical Substitution: A Research and Practice Agenda. Integr Environ Assess Manag. pre-print. doi:10.1002/ieam.4094. [accessed 2018 Aug 23]. https://setac.onlinelibrary.wiley.com/doi/abs/10.1002/ieam.4094.

U.S. EPA. 2012. Quantitative Structure Activity Relationship (QSAR) Guidance Document. [accessed 2019 Nov 9]. https://archive.epa.gov/pesticides/news/web/pdf/qsarguidance.pdf.

U.S. EPA. 2018. Strategic Plan to Promote the Development and Implementation of Alternative Test Methods Within the TSCA Program. Washington, D.C.: US EPA. Office of Chemical Safety and Pollution Prevention Report No.: EPA-740-R1-8004.

Vachon J, Campagna C, Rodriguez MJ, Sirard M-A, Levallois P. 2017. Barriers to the use of toxicogenomics data in human health risk assessment: A survey of Canadian risk assessors. Regul Toxicol Pharmacol. 85:119-123. doi:10.1016/j.yrtph.2017.01.008.

Waters MD, Fostel JM. 2004. Toxicogenomics and systems toxicology: aims and prospects. Nat Rev Genet. 5(12):936-948. doi:10.1038/nrg1493.

Whelan M, Eskes C. 2016. Evolving the Principles and Practice of Validation for New Alternative Approaches to Toxicity Testing. In: Validation of Alternative Methods for Toxicity Testing. Springer, Cham. (Advances in Experimental Medicine and Biology). p. 387-399. [accessed 2017 Nov 20]. https://link.springer.com/chapter/10.1007/978-3-31933826-2_15.

Williams R. 2016. Understanding and interpreting generalized ordered logit models. J Math Sociol. 40(1):7-20. doi:10.1080/0022250X.2015.1112384.

Winickoff DE, Mondou M. 2017. The problem of epistemic jurisdiction in global governance: The case of sustainability standards for biofuels. Soc Stud Sci. 47(1):7-32. doi:10.1177/0306312716667855.

Woolley D, Woolley A. 2017. Introduction to Toxicology: The Necessity of Measurement. In: Practical Toxicology. 3rd edition. Boca Raton, FL: CRC Press. p. 136. [accessed 2019 Nov 7]. http://www.crcnetbase.com/doi/abs/10.1201/978142004315010.

This article is protected by copyright. All rights reserved. 
REVISED - December 2019

Yakut E, Gündüz M, Demirci A. 2015. Comparison Of Classification Success Of Human Development Index By Using Ordered Logistic Regression Analysis And Artificial Neural Network Methods. J Appl Quant Methods. 10(3):15-34.

Yin RK. 2003. Case Study Research: Design and Methods. SAGE.

Zaunbrecher V, Beryt E, Parodi D, Telesca D, Doherty J, Malloy T, Allard P. 2017. Has Toxicity Testing Moved into the 21st Century? A Survey and Analysis of Perceptions in the Field of Toxicology. Environ Health Perspect. 125(8). doi:10.1289/EHP1435. [accessed 2018 Feb 7]. http://ehp.niehs.nih.gov/EHP1435.

Zeiger E. 1999. Federal interagency activities toward validation and regulatory acceptance of alternative tests. In: Toxicity Assessment Alternatives: Methods, Issues, Opportunities. Springer. p. 247-256. [accessed 2017 Jun 19]. http://link.springer.com/chapter/10.1007/978-1-59259-718-5_24.

Table 1: Sample description - demographics of the respondents

\begin{tabular}{|l|l|}
\hline & $n(\%)$ \\
\hline Year of last degree & \\
\hline $1969-1979$ & $4(2 \%)$ \\
\hline $1980-1989$ & $13(8 \%)$ \\
\hline $1990-1999$ & $29(17 \%)$ \\
\hline $2000-2009$ & $49(29 \%)$ \\
\hline $2010-2018$ & $70(41 \%)$ \\
\hline No degree completed & $6(4 \%)$ \\
\hline Employer & $95(56 \%)$ \\
\hline Academia & \\
\hline
\end{tabular}

This article is protected by copyright. All rights reserved. 
REVISED - December 2019

\begin{tabular}{|c|c|}
\hline Business/Industry & $21(12 \%)$ \\
\hline Government/Military & $29(17 \%)$ \\
\hline NGO & $2(1 \%)$ \\
\hline Consultant & 17 (10\%) \\
\hline Retired & $2(1 \%)$ \\
\hline Other & $5(3 \%)$ \\
\hline \multicolumn{2}{|l|}{ Region } \\
\hline Africa & $18(11 \%)$ \\
\hline Asia/Pacific & $14(8 \%)$ \\
\hline Europe & $62(36 \%)$ \\
\hline Latin America & 32 (19\%) \\
\hline North America & $45(26 \%)$ \\
\hline \multicolumn{2}{|c|}{$\begin{array}{l}\text { How active are you in the SETAC } \\
\text { community? }\end{array}$} \\
\hline Not at all active & $21(12 \%)$ \\
\hline Slightly active & $65(38 \%)$ \\
\hline Moderately active & $50(29 \%)$ \\
\hline
\end{tabular}

This article is protected by copyright. All rights reserved. 
REVISED - December 2019

\begin{tabular}{|l|l|}
\hline Very active & $27(16 \%)$ \\
\hline Extremely active & $8(5 \%)$ \\
\hline
\end{tabular}

Table 2: Ordered Logistic Regression - Determinants of perceptions of the viability of different test methods.

\begin{tabular}{|c|c|c|c|c|c|c|}
\hline Variables & 'omics & In vitro & In silico & HTS & ELS & $\begin{array}{l}\text { Conventio } \\
\text { nal }\end{array}$ \\
\hline $\begin{array}{l}\text { Years since last } \\
\text { degree }\end{array}$ & $\begin{array}{l}-0.023 \\
(0.017)\end{array}$ & $\begin{array}{l}0.000 \\
(0.017)\end{array}$ & $\begin{array}{l}-0.037^{*} \\
(0.02)\end{array}$ & $\begin{array}{l}-0.001 \\
(0.018)\end{array}$ & $\begin{array}{l}-0.01 \\
(0.027)\end{array}$ & $\begin{array}{l}0.124^{* *} \\
(0.051)\end{array}$ \\
\hline Non-Academic & $\begin{array}{l}-0.061 \\
(0.476)\end{array}$ & $\begin{array}{l}0.405 \\
(0.53)\end{array}$ & $\begin{array}{l}1.265^{* *} \\
(0.592)\end{array}$ & $\begin{array}{l}0.339 \\
(0.561)\end{array}$ & $\begin{array}{l}-0.6765 \\
(0.738)\end{array}$ & $\begin{array}{l}-0.353 \\
(0.678)\end{array}$ \\
\hline $\begin{array}{l}\text { Conventional testing } \\
\text { limitations }\end{array}$ & $\begin{array}{l}-0.138 \\
(0.147)\end{array}$ & $\begin{array}{l}0.059 \\
(0.161)\end{array}$ & $\begin{array}{l}0.241 \\
(0.183)\end{array}$ & $\begin{array}{l}-0.230 \\
(0.164)\end{array}$ & $\begin{array}{l}0.132 \\
(0.23)\end{array}$ & $\begin{array}{l}-0.087 \\
(0.275)\end{array}$ \\
\hline Whole animal studies & $\begin{array}{l}-0.12 \\
(0.141)\end{array}$ & $\begin{array}{l}-0.263 * \\
(0.158)\end{array}$ & $\begin{array}{l}- \\
0.334^{* *} \\
(0.17)\end{array}$ & $\begin{array}{l}0.067 \\
(0.155)\end{array}$ & $\begin{array}{l}0.107 \\
(0.211)\end{array}$ & $\begin{array}{l}0.144 \\
(0.271)\end{array}$ \\
\hline Paracelsus & $\begin{array}{l}0.148 \\
(0.122)\end{array}$ & $\begin{array}{l}-0.205 \\
(0.135)\end{array}$ & $\begin{array}{l}0.147 \\
(0.146)\end{array}$ & $\begin{array}{l}0.206 \\
(0.146)\end{array}$ & $\begin{array}{l}-0.175 \\
(0.183)\end{array}$ & $\begin{array}{l}0.507 * * \\
(0.244)\end{array}$ \\
\hline Molecular level origin & $\begin{array}{l}-0.045 \\
(0.134)\end{array}$ & $\begin{array}{l}-0.104 \\
(0.142)\end{array}$ & $\begin{array}{l}0.063 \\
(0.154)\end{array}$ & $\begin{array}{l}0.093 \\
(0.152)\end{array}$ & $\begin{array}{l}0.144 \\
(0.217)\end{array}$ & $\begin{array}{l}0.25 \\
(0.349)\end{array}$ \\
\hline $\begin{array}{l}\text { Collaboration w/ } \\
\text { academics }\end{array}$ & $\begin{array}{l}0.168 \\
(0.182)\end{array}$ & 0.013 & 0.113 & -0.02 & $\begin{array}{l}- \\
0.582 * *\end{array}$ & \\
\hline
\end{tabular}

This article is protected by copyright. All rights reserved. 
REVISED - December 2019

\begin{tabular}{|c|c|c|c|c|c|c|}
\hline & & $(0.207)$ & $(0.213)$ & $(0.220)$ & $(0.282)$ & \\
\hline $\begin{array}{l}\text { Collaboration w/ } \\
\text { industry }\end{array}$ & $\begin{array}{l}- \\
0.722^{* *} \\
* \\
(0.227)\end{array}$ & $\begin{array}{l}-0.393 * \\
(0.231)\end{array}$ & $\begin{array}{l}- \\
0.796 * * \\
* \\
(0.276)\end{array}$ & $\begin{array}{l}-0.512 * \\
(0.284)\end{array}$ & $\begin{array}{l}0.246 \\
(0.325)\end{array}$ & \\
\hline $\begin{array}{l}\text { Collaboration w/ } \\
\text { government }\end{array}$ & $\begin{array}{l}0.089 \\
(0.196)\end{array}$ & $\begin{array}{l}0.119 \\
(0.221)\end{array}$ & $\begin{array}{l}0.095 \\
(0.266)\end{array}$ & $\begin{array}{l}-0.021 \\
(0.214)\end{array}$ & $\begin{array}{l}0.338 \\
(0.306)\end{array}$ & \\
\hline $\begin{array}{l}\text { Collaboration w/ } \\
\text { NGOs }\end{array}$ & $\begin{array}{l}0.481^{*} \\
(0.265)\end{array}$ & $\begin{array}{l}-0.101 \\
(0.272)\end{array}$ & $\begin{array}{l}-0.044 \\
(0.309)\end{array}$ & $\begin{array}{l}0.615^{* *} \\
(0.283)\end{array}$ & $\begin{array}{l}0.304 \\
(0.471)\end{array}$ & \\
\hline $\begin{array}{l}\text { Collaboration w/ } \\
\text { consultants }\end{array}$ & $\begin{array}{l}0.047 \\
(0.256)\end{array}$ & $\begin{array}{l}0.263 \\
(0.286)\end{array}$ & $\begin{array}{l}1.139 * * \\
* \\
(0.358)\end{array}$ & $\begin{array}{l}0.155 \\
(0.283)\end{array}$ & $\begin{array}{l}0.739 * \\
(0.445)\end{array}$ & \\
\hline $\begin{array}{l}\text { Satisfaction with } \\
\text { regulatory testing }\end{array}$ & $\begin{array}{l}0.414 \\
(0.36)\end{array}$ & $\begin{array}{l}0.159 \\
(0.385)\end{array}$ & $\begin{array}{l}0.718 \\
(0.464)\end{array}$ & $\begin{array}{l}0.473 \\
(0.413)\end{array}$ & $\begin{array}{l}- \\
1.259 * * \\
(0.547)\end{array}$ & $\begin{array}{l}-0.095 \\
(0.685)\end{array}$ \\
\hline
\end{tabular}

Knowledge level: $\quad 0.246$

'omics

$(0.180)$

Knowledge level: in

$0.511^{* *}$

vitro

$(0.212)$

Knowledge level: in silico

$0.727^{* *}$

$(0.233)$

Knowledge level:

0.286

High-throughput

$(0.242)$

This article is protected by copyright. All rights reserved. 
REVISED - December 2019

screening

Knowledge level: $\quad 0.588^{* *}$

Early life stage in vivo

$(0.301)$

\begin{tabular}{|c|c|c|c|c|c|c|}
\hline \multirow[t]{4}{*}{ Threshold (0->1) } & - & - & - & - & - & \multirow[t]{2}{*}{$1.532 * * *$} \\
\hline & $2.807^{* *}$ & $2.496 * *$ & $1.737 * *$ & $1.971^{* *}$ & $3.768 * *$ & \\
\hline & $*$ & * & & & & $(0.552)$ \\
\hline & & (0.639) & (0.599) & (0.619) & $(0.952)$ & \\
\hline \multirow[t]{4}{*}{ Threshold (1->2) } & -0.753 & - & -0.670 & & - & \\
\hline & $(0471)$ & $1.075^{* *}$ & $(0.558)$ & & $2.482 * *$ & \\
\hline & & $(0.542)$ & & -0.346 & $\pi$ & \\
\hline & & & & $(0.562)$ & $(0.821)$ & \\
\hline \multirow[t]{2}{*}{ Threshold (2->3) } & $0.803^{*}$ & 0.434 & 0.887 & $0.982 *$ & \multirow{2}{*}{$\begin{array}{l}-1.325^{*} \\
(0.781)\end{array}$} & \\
\hline & $(0.464)$ & $(0.53)$ & $(0.558)$ & $(0.564)$ & & \\
\hline \multirow[t]{3}{*}{ Log-Likelihood } & - & - & - & - & - & \multirow[t]{3}{*}{-38.45524} \\
\hline & 166.898 & 142.175 & 123.969 & 132.679 & 79.2791 & \\
\hline & 6 & 6 & 4 & 9 & 6 & \\
\hline \multirow[t]{2}{*}{ McFadden's $\mathrm{R}^{2}$} & 0.06869 & 0.04882 & 0.14863 & 0.04410 & 0.11320 & \multirow[t]{2}{*}{0.1786285} \\
\hline & & 04 & 4 & 11 & 31 & \\
\hline \multirow[t]{2}{*}{ AIC } & 365.797 & 316.351 & 279.938 & 297.359 & 190.558 & \multirow[t]{2}{*}{92.91047} \\
\hline & 3 & 3 & 7 & 8 & 3 & \\
\hline $\mathrm{N}$ & 141 & 146 & 132 & 110 & 144 & 153 \\
\hline
\end{tabular}

Note: ${ }^{* *} p<0.01 ;{ }^{* *} p<0.05 ;{ }^{*} p<0.1$ (standard errors in parentheses). Threshold (0->1) indicates category 0 if the value of threshold parameter is less than or equal to -2.807 ; Threshold (1->2) indicates category 1 if the value of threshold parameter is higher than 2.807 and less than or equal to -0.753 and so forth. See Appendix 2 in supplemental data for further detail.

This article is protected by copyright. All rights reserved. 


\section{University Library}

\section{- M M I N E R VA \\ A gateway to Melbourne's research publications}

Minerva Access is the Institutional Repository of The University of Melbourne

Author/s:

Mondou, M;Hickey, GM;Rahman, HMT;Maguire, S;Pain, G;Crump, D;Hecker, M;Basu, N

Title:

Factors Affecting the Perception of New Approach Methodologies (NAMs) in the Ecotoxicology Community

Date:

2020-03-01

Citation:

Mondou, M., Hickey, G. M., Rahman, H. M. T., Maguire, S., Pain, G., Crump, D., Hecker, M. \& Basu, N. (2020). Factors Affecting the Perception of New Approach Methodologies (NAMs) in the Ecotoxicology Community. Integrated Environmental Assessment and Management, 16 (2), pp.269-281. https://doi.org/10.1002/ieam.4244.

Persistent Link:

http://hdl.handle.net/11343/275268 